\title{
A IMPORTÂNCIA DA ANÁLISE AUDITIVA PARA OS ESTUDOS ACÚSTICOS
}

\author{
THE IMPORTANCE OF AUDITORY ANALYSIS TO THE ACOUSTIC STUDIES
}

\author{
Mariane Carvalho \\ UNESP - Araraquara
}

RESUMO: Este artigo pretende fazer uma correlação entre os dados acústicos e auditivos, levando em consideração a grande dificuldade que existe, atualmente, quando se trata dos estudos auditivos. Nossa intenção é mostrar que o fato de observar apenas os dados físicos e deixar de lado a questão auditiva pode ser um fato muito comprometedor, pois a percepção da fala é o que motiva o uso da linguagem entre as pessoas. No entanto, as análises físicas são necessárias. O que não pode ocorrer é que elas dispensem as interpretações auditivas. Portanto, nossa intenção é provar que essa correlação é tanto possível quanto viável. Para isso, esta análise descreve a estrutura fonológica da entoação, a partir da gravação de um pequeno trecho do livro História sem fim (sd). O trabalho está embasado em duas linhas teóricas. Uma das abordagens diz respeito ao estudo auditivo, desenvolvido por Halliday (1970) e adaptado por Cagliari (1982/2007) para a análise dos dados do português brasileiro. A outra é de base acústica e segue o modelo de análise autossegmental, desenvolvido por Pierrehumbert (1980).

PALAVRAS-CHAVE: Análise acústica; Análise auditiva; Halliday; Pierrehumbert

ABSTRACT: This article intends to make a correlation between acoustic and auditory data, considering the great difficulty that exists today when it comes to auditory studies. Our intention is to show that the fact to take into account only the physical data and leave aside the auditory question can be very compromising, because the perception of speech is what motivates the use of language between people. However, the physical analyzes are needed. What can not happen is that they waive the auditories interpretations. Therefore, our intention is to prove that this correlation is as much possible as feasible. For this, this analysis describes the phonological structure of intonation, from recording a short passage from the book História sem fim (The Neverending Story) (sd). The study is grounded in two theoretical lines. One of them is concerned with the auditory approach (Halliday, 1970 and Cagliari, 2007/1982). The other, is the acoustic approach developed by Pierrehumbert (1980).

KEYWORD: Auditory analysis; Acoustic analysis; Halliday; Pierrehumbert 


\section{Revista do SELL}

v. $4, n^{\circ} .1$

ISSN: $1983-3873$

\section{Introdução e delimitação do tema}

The realization that there are two sides to the understanding of the fact of speech - the physical and the psychological - and two main techniques of recognition which complement rather than alternate with each other, has led many linguists and phoneticians to criticize any approach which would be based on only one or the other'.

(CRYSTAL, 1969, p. 3).

Mesmo dita há mais de 30 anos, a citação acima aborda um assunto atual e abre espaço para a discussão do tema deste trabalho. Isto é, a importância das análises auditivas para os estudos acústicos. Segundo Crystal, a possibilidade de trabalhar concomitantemente com uma análise acústica e auditiva sempre foi alvo de muita discussão entre os linguistas e foneticistas. Essa polêmica teve início com o crescente interesse pelos estudos acústicos em detrimento da questão psicológica, auditiva. Diante disso, surge uma divisão entre os foneticistas tradicionais, que têm como base uma interpretação auditiva e os foneticistas de laboratórios, que partem de uma interpretação acústica.

Considerando então a importância dessa questão, o presente artigo tem como objetivo desmistificar a ideia de que somente uma análise acústica ou uma análise auditiva seria suficiente para os estudos acústicos. Pelo contrário, queremos mostrar que a correlação entre esses dois fenômenos é o passo mais viável a seguir, pois nas transcrições auditivas, as análises são menos detalhadas, baseando-se em padrões interpretativos mais gerais. Em compensação, temos a precisão dos dados acústicos. Por isso, é da comparação entre ambos que podemos estabelecer as faixas de frequência que são importantes, já que pequenas variações da frequência fundamental (F0) não devem ser consideradas como relevantes para a análise linguística. Segundo Cagliari (2010), não é possível determinar esses limites somente por meio da estatística, uma vez que existem outros fatores, como a tessitura, que podem interferir na avaliação da F0. De acordo com o autor, os "Tratamentos estatísticos, em geral, evidenciam apenas grandes contrastes ou se aplicam em condições de fala muito controladas" (CAGLIARI, 2010, p. 3). Diante disso, a descrição de um fenômeno ganha uma maior qualidade quando uma abordagem acústica vem auxiliada pela análise auditiva, ou o contrário.

\footnotetext{
${ }^{1}$ A compreensão de que há dois lados para o entendimento da fala - o físico e o psicológico - e duas técnicas principais de reconhecimento que se complementam, ao invés de alternarem entre si, levou muitos linguistas e foneticistas a criticarem qualquer outra abordagem que estivesse baseada apenas em uma das duas [tradução nossa].
} 


\section{Revista do SELL \\ v. $4, n^{\circ} .1$ \\ ISSN: $1983-3873$}

Este trabalho embasa-se em duas perspectivas teóricas diferentes: uma de base auditiva e a outra de base acústica. A primeira é uma abordagem sistêmico-funcional e diz respeito ao modelo teórico proposto por M.A.K. Halliday (1970), adaptado para o Português do Brasil (PB) por Cagliari (1982/2007). A segunda, pertence à gramática gerativa, desenvolvida por Pierrehumbert (1980). A opção por esses dois modelos devese ao fato de eles serem os mais desenvolvidos no que diz respeito à descrição da entoação dentro do componente fonológico da gramática funcional e gerativa.

Para isso, o presente trabalho inicia-se com uma breve discussão acerca dos estudos acústicos e auditivos ao longo do século. Posteriormente, apresentamos os dois modelos teóricos utilizados e propomos um diálogo entre eles. O tópico seguinte será destinado à descrição da metodologia utilizada para a correlação acústica e auditiva e à apresentação e análise do corpus. Finalizaremos com o esboço dos resultados obtidos e com a conclusão a respeito do questionamento proposto.

\section{O embate acústico e auditivo}

Os primeiros computadores pessoais aparecem no início da década de 70 . Até então, os fenômenos fonéticos eram descritos através de uma interpretação auditiva, a partir de uma descrição fonológica. Posteriormente, essa tradição acaba perdendo espaço para as análises acústicas. Conforme Cagliari (2007b), o estudo acústico da fala teve início no final do século XIX e começo do século $X X$, devido ao aparecimento de muitos laboratórios de fonética, que permitiram, entre outras coisas, um maior aperfeiçoamento das pesquisas. No entanto, também vieram novos linguistas que, sem um conhecimento adequado passaram a considerar a interpretação acústica como o mais correto e válido instrumento de análise.

De acordo com o autor (CAGLIARI, 2007b), o interesse desses laboratórios era aprimorar os sistemas de telefonia, bem como desenvolver um sistema de fala sintética. Com isso, a tradição dos estudos auditivos acabou perdendo espaço e, como consequência, criou-se uma divisão, por alguns estudiosos, entre fonética e fonologia. Ao primeiro, era atribuída uma investigação física e experimental aos sons da fala e, ao segundo, uma interpretação auditiva "[...] da representação mental do aspecto sonoro do sistema das línguas" (CAGLIARI et alli, 2012, p.1). Conforme Pike (1945), os instrumentalistas acreditam que as suposições feitas pelos adeptos de uma análise auditiva quanto à intensidade, frequência fundamental e duração são muito imprecisas e 


\section{Revista do SELL \\ v. $4, n^{\circ} .1$ \\ ISSN: $1983-3873$}

não têm validade. Por outro lado, segundo o autor, os analistas auditivos rejeitam a tendência dos instrumentalistas em medir qualquer coisa, deixando de lado, muitas vezes, a questão linguística do fenômeno.

Assim, enquanto as interpretações acústicas cresciam cada vez mais, as interpretações auditivas passaram a ter menos valor e a análise linguística é deixada em segundo plano. Para Cagliari (2007b), esse fenômeno somente fez surgir um "caos linguístico", pois com a explosão de trabalhos acústicos, as interpretações linguísticas mais antigas foram substituídas pelas interpretações estatísticas e o falante vivo foi substituído por um informante de laboratório. Isso, segundo o foneticista prejudica as análises linguísticas, pois a estatística não pode definir o que é invariante e o que é variante, porque se trata de uma questão de qualidade do sistema e não de quantidade.

Mesmo assim, alguns foneticistas consideram válidos somente dados avaliados instrumentalmente e outros, por sua vez, dispensam os dados instrumentais, considerando que a fala só poderia ser explicada linguísticamente com relação ao sistema da língua. Contudo, em meio a essa divisão há aqueles foneticistas que reconhecem que a melhor saída está na cooperação entre as análises instrumentais e auditivas, já que

[...] even with simpler, speedier, cheaper, more sensitive and reliable instruments to analyse a corpus of speech than exist at present, the results would still be of limited value in trying to reach any understanding of the meaning of such vocal effects as intonation and other prosodic features when perceived by the listener, for the obvious reason that the instrumental analyses produce pictures of speech which are too sensitive to detail to provide any clear pattern. The physical correlates of those features, or accumulations of features, which are of linguistic significance for the native speaker, are obscured by the presence of a large amount of accompanying but less relevant (or irrelevant) phenomena ${ }^{2}$. (CRYSTAL, 1969, p. 3).

Do mesmo lado de Crystal estão F. Winckel (1968), que acredita na capacidade do ouvinte identificar os sinais linguísticos a partir de uma análise acústica prévia; CruzFerreira (1983), que lamenta que alguns pesquisadores tenham deixado de lado o

2[...] mesmo com os mais simples, rápidos, baratos, mais sensíveis e confiáveis instrumentos do que os que existem até o momento para a análise de um corpus de fala, os resultados para se chegar a qualquer compreensão dos efeitos vocálicos, como a entoação e outras características prosódicas quando percebidas pelo ouvinte, ainda teriam valores limitados, pela simples razão de que as análises instrumentais produzem imagens da fala que são muito sensíveis ao detalhe para proporcionar qualquer padrão claro. Os correlatos físicos desse recurso ou acumulação dessas funções, que têm importância linguística para o falante nativo, são obscurecidos pela presença de uma grande quantidade acrescentada, mas menos relevante (ou irrelevante) de um fenômeno.

[tradução nossa]. 


\section{Revista do SELL \\ v. $4, n^{\circ} .1$ \\ ISSN: $1983-3873$}

caráter perceptual da entoação, já que a relevância linguística não é decidida somente pelo caráter físico da fala, mas também pelo perceptual; Pike (1945), que acredita que cada um dos dois métodos tem seu lado negativo e seu lado positivo. Por exemplo, para o autor, as análises auditivas não são tão eficientes quanto às análises acústicas no que diz respeito à descrição e à medição das características das ondas sonoras. Por outro lado, nenhum pesquisador pode afirmar, a partir de análises físicas, o que determinadas ondas sonoras significam. Já nas análises auditivas, é possível questionar o falante nativo e descobrir, mesmo que vagamente, o significado dos sinais linguísticos. Além desses autores, também podemos citar Currie (1979) e Martin (1975); Daniel Jones (1960); Bertil Malmberg (1968) e Boix (1991); Ladefoged (1967), Ball; Rahilly, (1999), Gunnar Fant (1967), D. Fry (1973), J. Catford (1988), Keith Johnson (2003), Yi Xu (2009), entre outros.

Assim como eles, é preciso que outros foneticistas reconheçam a necessidade de se fazer análises a partir dos dois pontos de vista. Não faz sentido desenvolver um estudo que englobe somente uma análise acústica ou somente uma análise auditiva, já que as duas abordagens são complementares. Segundo Cagliari et alli, (2012), aqueles que acreditam que a análise acústica é autossuficiente incorrem no erro de analisar apenas o aspecto físico dessa realidade, porque toda atribuição de segmentos acústicos a uma unidade fonética (vogal, consoante, entoação, entre outros) só pode ser feita se o sistema da língua estiver avaliando, justificando ou negando as análises feitas. $\mathrm{O}$ confronto com o sistema linguístico é imprescindível até mesmo quando estamos operando com um reconhecimento automático da fala, pois é o regulador e avaliador das análises acústicas automáticas.

Portanto, mesmo que atualmente os trabalhos acústicos sejam numerosos, de acordo com Cagliari et alli (2012), a decisão linguística sempre acaba caindo em um julgamento auditivo do foneticista que atribui um símbolo (categoria) a um som.

É por tudo isso que acreditamos que a melhor análise linguística é aquela que junta à descrição acústica uma interpretação linguística ou vice-versa. Pois, de acordo com Ladefoged (1973) uma descrição fonética só é considerada adequada se tiver o mesmo significado para todos os que a usam.

Em vista do que foi discutido, fazemos a seguir uma descrição dos dois modelos escolhidos para análise, um de base auditiva e outro de base acústica. Logo de início, a intenção é propor um diálogo entre eles e mostrar que apesar de formalmente diferentes, é possível encontrar semelhanças. Seguido disso, aplicamos as duas 


\section{Revista do SELL \\ v. $4, n^{\circ} .1$ \\ ISSN: $1983-3873$}

abordagens escolhidas à análise do nosso corpus, a fim de provarmos a possibilidade desse tipo de análise.

\section{Os modelos teóricos: entre as diferenças, as semelhanças}

M.A.K Halliday (1970) descreve a entoação a partir de uma proposta sistêmico funcionalista que entende as funções linguísticas como uma relação entre forma e estrutura. Os funcionalistas acreditam, de acordo com Lyons (1987), que as funções da linguagem determinam as estruturas fonológicas gramaticais e semânticas. Dessa forma, o uso da linguagem é modelado pelo sistema linguístico.

A teoria de Pierrehumbert, por sua vez, é conhecida como teoria métrica autossegmental (AM) da entoação. A fonologia autossegmental procura investigar os aspectos fonológicos das línguas a partir do seu componente fonológico, como um conjunto de subsistemas em interação, cada um deles apresentando aspectos particulares e específicos. O modelo teórico da autora foi construído a partir da teoria métrica de Liberman (LIBERMAN, 1975; LIBERMAN e PRINCE, 1977).

Halliday, não opta somente pela fonética ou fonologia, ele une as duas, já que segundo ele, o trabalho individual leva a distorções. Diferentemente de Pierrehumbert, o autor acredita não ser possível descrever a entoação exclusivamente com a análise (auditiva ou acústica) fonética, bem como não é possível associar os padrões dos tons às categorias gramaticais diretamente. Isso porque essas descrições são independentes umas das outras. "Ocasionalmente, há uma relação entre categorias gramaticais de outro nível com o sistema entoacional, mas não há nenhuma categoria que exija um padrão entoacional único e exclusivo ou vice-versa" (CAGLIARI, 2011, p. 3). Mesmo assim, conforme Cagliari, Pierrehumbert considera a característica abstrata e geral dos padrões entoacionais.

Para Halliday, a entoação, como um processo gramatical, depende de outros itens, como a sintaxe, a pragmática e a semântica. Essa visão vai contra o que Pierrehumbert faz. Para a autora a entoação não é algo sistemático e fluído, enquanto, para o autor tudo na língua é sistemático, com limites controlados de variação. Ambos são sistemas fonológicos, e não um arranjo ocasional de dados. Isso é justificado quando o autor diz que os contrastes fonológicos são tratados por um sistema de termos discretos, aplicando-se tanto para os sistemas fonológicos quanto para os contrastes gramaticais. 


\section{Revista do SELL}

v. $4, n^{\circ} .1$

ISSN: $1983-3873$

Como corpus, Halliday trabalha com a análise do inglês britânico, mais especificamente com a variedade de inglês RP (receive pronunciation). Pierrehumbert, com a variação standard do inglês americano. A descrição dos dialetos feita pelos dois autores, conforme Cagliari (2011), é um meio de mostrar que uma mesma língua pode apresentar padrões entoacionais distintos. Além disso, os autores também mostram que não existe uma relação entre o contraste de variação melódica e o significado lexical, como acontece com o tailandês ou com o vietnamita, ambas línguas tonais. Conforme Cagliari, para Halliday e Pierrehumbert é possível descrever as línguas tonais e entoacionais por meio do mesmo modelo.

Para os padrões melódicos, Halliday atribui valores aos pés rítmicos. Os pés $(P)$ são descritos segundo a visão de Abercrombie (1964). Eles estão relacionados ao componente gramatical por meio de uma organização sintática entre os enunciados, a partir de dois componentes: o tema e o rema, que com objetivos informativos diferentes apresentam características fonológicas próprias. Esses componentes são nomeados "componente tônico" (CT) e "componente pretônico" (CPT). A separação entre eles é feita pelo grupo tonal (GT), sendo os pés rítmicos responsáveis por sua estrutura. O CT caracteriza os elementos sintáticos, é obrigatório e está presente em cada GT. O CPT, por sua vez, é opcional, responsável por caracterizar as variações entoacionais e as atitudes do falante. A divisão entre eles é dada pela sílaba tônica.

Pierrehumbert também divide o enunciado, nomeados por ela de "componente nuclear" e "pré-nuclear". No entanto, ela não fala em níveis gramaticais. O GT também não aparece na sua nomenclatura. Mas, por outro lado, podemos compará-lo com o que a autora chama de tunes, isto é, as entidades linguísticas que estão alinhadas com o texto por meio de regras linguísticas que apresentam um padrão determinado.

O CPT e o componente pré-nuclear são fonologicamente secundários nas duas descrições, já que "Somente secundariamente, o que ocorre nesse contexto passa a ser relevante, definindo atitudes do falante, padrões sintáticos (enumerações...), semânticos (atitudes do falante...) ou pragmáticos (atos de fala...). (CAGLIARI, 2011, p. 3-4).

No modelo de Halliday, os níveis entoacionais (alto, meio-alto, médio, meio-baixo e baixo) são definidos a partir da configuração do contorno melódico no CT. Em Pierrehumbert, há apenas dois tons principais $\mathrm{H}$ (high) e $\mathrm{L}$ (low). Essa anotação ocorre através da sílaba tônica frasal (o foco entoacional do enunciado) e do tom de fronteira final. 


\section{Revista do SELL \\ v. $4, n^{\circ} .1$ \\ ISSN: $1983-3873$}

Em relação à atribuição de tonicidade as sílabas são classificadas pelos autores entre tônicas e átonas, sendo estas desconsideradas na análise entoacional. As sílabas de maior proeminência são aquelas que apresentam a marca mais notável do enunciado, compreendendo a parte do enunciado que o falante julga como sendo a mais importante (o foco do GT). Elas são nomeadas por Halliday de sílaba tônica saliente (STS) e por Pierrehumbert de pitch accent. A sua localização é definida pelo autor através do foco entoacional do enunciado ou onde ocorre a mudança mais notável da direção do contorno entoacional. A foneticista recorre à estrutura métrica do enunciado.

Quanto à anotação dos padrões entoacionais, Halliday utiliza cinco tons melódicos primários, numerados de 1 a 5 e dois compostos 13 e $53^{3}$. Esses tons são obtidos por meio de uma abstração fonológica. A opção por um ou por outro depende do sentido que eles têm na língua, de modo que o sentido fica determinado pelo uso.

Pierrehumbert também parte de uma abstração fonológica, mas para isso, ela precisa investigar as regras que mapeiam essas representações fonológicas em representações fonéticas, o que não precisa ser feito no modelo do autor. A descrição da autora é feita apenas com dois tons, um alto (high - H) e outro baixo (low - L), os quais são gerados por um sistema fonológico, como parte da gramática da língua. Como Pierrehumbert não trabalha com um tom intermediário, nesse caso o médio, ocorre um prejuízo em sua descrição, pois, algumas vezes, a autora acaba traduzindo um tom médio como um tom alto ou baixo, o que não acontece no modelo funcional. Pierrehumbert também não trabalha com tons compostos. Esse tipo de tom em seu modelo representa um espraiamento dentro de uma sílaba e ocorre, normalmente, com as sílabas tônicas, que costumam ser as mais longas em um enunciado. De acordo com Cagliari (2011), esse fato mostra que Pierrehumbert não conjectura uma variação no sistema.

No que diz respeito ao significado entoacional, Pierrehumbert descreve a entoação segundo as características da frequência fundamental (F0), relacionando fatos acústicos a fonológicos. A autora não compara os usos do padrão de F0 que são fonologicamente distintivos, apenas faz uma descrição superficial do significado ou uso de algum contorno específico. Como a autora trabalha no interior da gramática gerativa, que separa o componente fonológico do sintático e do semântico, cada um operando

\footnotetext{
${ }^{3}$ Para o Português do Brasil (PB), Cagliari propôs o uso de 6 tons primários, numerados de 1 a 6 e três tons compostos, 13, 53 e 63.
} 


\section{Revista do SELL \\ v. $4, n^{\circ} .1$ \\ ISSN: $1983-3873$}

com regras próprias, para ela, somente interessa a observação da curva entoacional e não o que o falante quis dizer com o enunciado.

Envolvido em um modelo funcional, Halliday, por outro lado, relaciona os padrões entoacionais às atitudes do falante. Assim, o autor explica o sistema linguísticos não só por meio de uma visão extrínseca como também intrínseca das funções da linguagem.

Para Pierrehumbert, atribuir padrões sintáticos aos tons não é possível, pois eles são extremamente dependentes do contexto. De acordo com ela, a impressão de que a entoação varia dependendo do contexto semântico de um enunciado ou dos objetivos do falante também não é significativa, pois, segundo ela, um mesmo padrão pode ser usado, por exemplo, tanto em perguntas interrogativas quanto em enunciados afirmativos. Halliday também concorda com essa afirmação, mas, para o autor, os padrões entoacionais podem definir, sim, os aspectos semânticos, sintáticos e pragmáticos associados aos enunciados. Pierrehumbert não poderia levar esse tipo de questão em consideração, uma vez que ela está interessada no lado acústico da entoação, optando por estudar os valores quantitativos dos tons.

A noção de marcação para o contexto final do enunciado é uma característica comum às duas abordagens, já que de acordo com Pierrehumbert, (1980, p. 26): “[...] The end of the intonational phrase has distinctive tonal characteristics, apart from those attributable to the picth accents" 4. Em Halliday, essa anotação é feita através de símbolos visuais e linhas horizontais, marcando o movimento da altura melódica para cada pé no final do enunciado. Na anotação da autora, o contexto final é indicado por um símbolo de (\%) ao lado de cada unidade tonal ( $\mathrm{H} \%$ ou $\mathrm{L} \%)$.

Outro ponto comum entre as duas propostas é o reconhecimento de pausas entre os enunciados. De acordo com a autora, seria uma espécie de pausa interna, ocorrendo onde há uma pausa não hesitacional ou onde se pode introduzir uma pausa sem que o contorno entoacional seja prejudicado. Em Halliday as pausas são incorporadas à descrição do ritmo, podendo ocupar lugares silábicos no nos pés ou, até mesmo, na duração de pés inteiros. O autor associa as pausas às questões sintáticas e semânticas, diferentemente do que faz Pierrehumbert.

Quanto à tessitura, Halliday mostra que esse efeito iguala realizações fonéticas diferentes no sistema, "[...] mas que apresentam um contraste estabelecido como sendo o mesmo no nível fonológico." (CAGLIARI, 2011, p.5). Conforme Cagliari, uma sílaba

\footnotetext{
4 "O final da frase entoacional tem características tonais distintivas, além daquelas atribuídas aos pitch accents" [tradução nossa].
} 


\section{Revista do SELL \\ v. $4, n^{\circ} .1$ \\ ISSN: $1983-3873$}

pode apresentar uma variação da altura melódica de acordo com o valor de F0, mas permanecer sendo alta ou baixa, por exemplo. Isso ocorre, diz o autor, porque, mesmo com a variação acústica, o que caracteriza um tom não é a realização fonética de um enunciado, mas o valor fonológico atribuído a ele.

Em Pierrehumbert a tessitura pode ser comparada à discussão sobre as regras de downstep. De acordo com Cagliari, as variações no valor de $\mathrm{H}$ e $\mathrm{L}$ são um fato fonético e não fonológico e a tessitura é um fato fonético e fonológico. Entretanto, "[...] sua função não é re-ordenar os valores da F0, mas indicar marcas discursivas, como enunciados parentéticos ou enfatizados (por exemplo, em altura melódica de falseto)." (CAGLIARI, 2011, p. 6).

Por fim, outro distanciamento entre as duas metodologias incorre no ponto principal deste artigo, ou seja, o auditivo (Halliday) e o acústico (Pierrehumbert). A autora dispensa a análise auditiva, pois acredita que as abordagens que fazem uma representação da entoação mais abstrata (embora a descrição auditiva não seja exatamente uma interpretação mais abstrata), apresentam falhas.

No entanto, Pierrehumbert apenas critica o modelo de transcrição auditiva e não caracteriza, significativamente, quais seriam esses "gross errors". Ela justifica sua opinião afirmando que primeiro, ela precisa obter os seus dados para, depois, chegar a uma conclusão sobre os efeitos auditivos em uma análise entoacional. Porém, no decorrer da sua tese isso não é feito. Mesmo assim, há evidências, implícitas, na análise do seu corpus que a autora também precisou de um respaldo auditivo e não se limitou somente à análise acústica da F0, pois sendo alguns segmentos surdos, eles só poderiam ter sido decididos por meio de uma interpretação auditiva.

Halliday, por outro lado, apesar de dispensar a análise acústica, não faz nenhuma crítica quanto ao modelo e nem sequer invalida o seu uso.

Sendo assim, ao propormos um paralelo entre as duas perspectivas teóricas, nossa intenção foi mostrar que embora pareçam muito diferentes, os modelos aproximam-se e permitem, assim como afirma Cagliari (2011, p. 17) "[...] passar uma análise realizada em um modelo para uma análise no outro modelo". Esse fato também valida o nosso trabalho, mostrando que é possível desenvolver uma análise entoacional por meio da união entre esses dois modelos. 


\section{Revista do SELL}

v. $4, n^{\circ} .1$

ISSN: $1983-3873$

\section{Descrição do corpus e procedimentos de análise O corpus}

O corpus da análise faz parte de um pequeno trecho do livro História sem fim de Michael Ende (sd). O material sonoro selecionado foi lido por um homem de 65 anos, falante do dialeto paulista da cidade de Araraquara e com instrução superior completa. Atualmente, o falante atua como professor do ensino superior. A preferência por essa região deve-se, unicamente, à facilidade de acesso entre o pesquisador e o falante. Além disso, o interesse desse estudo não é observar as diferenças entoacionais regionais, mas, por outro lado, correlacionar dados acústicos e auditivos, como mencionado. Optamos por selecionar somente um falante devido à extensão do trabalho, uma vez que o texto será analisado a partir do modelo proposto por Halliday (1970) e Cagliari (1982/2007), sendo segmentado em trechos correspondentes aos grupos tonais, pausas, pés, sílaba tônica saliente e de acordo com o modelo de Pierrehumbert (1980). Além disso, trata-se de um trabalho de natureza qualitativa, que não tem por finalidade enumerar os dados, mas sim descrever os fatos.

Com relação à análise acústica, o texto foi segmentado em trechos correspondentes aos grupos tonais, para facilitar a análise, que não comporta longos trechos gravados. Os dados foram processados através do programa PRAAT, desenvolvido por Paul Boersma and David Weenink, do Institute of Phonetic Sciences. A gravação foi feita em uma taxa de amostragem de $22050 \mathrm{~Hz}$.

A gravação do corpus foi processada em um ambiente acusticamente adequado, via microfone unidirecional, modelo Microsoft LifeChat LX-3000. Tanto a gravação quanto o teste perceptivo foram feitos na própria Universidade (UNESP / FCL-AR). Como não dispomos de um laboratório acusticamente isolado, o ambiente escolhido para a gravação foi o que apresentou o mínimo de ruído possível, para não interferir na qualidade do áudio.

Posteriormente, o texto foi segmentado em 15 enunciados correspondentes a $22^{5}$ grupos tonais. Também foi feita a transcrição fonética ${ }^{6}$ e ortográfica de cada um dos enunciados. Em seguida, as frases foram descompactadas e subdividas em três níveis: 1) segmentos, 2) sílabas e 3) palavras. Esse método foi feito a partir do TextGrid do PRAAT e através da observação das informações carreadas pelo espectrograma.

\footnotetext{
${ }^{5}$ Não será possível apresentar a análise feita para todos os tons encontrados, já que as análises são muito extensas para a quantidade de páginas disponíveis.

${ }^{6} \mathrm{~A}$ transcrição fonética seguiu o modelo do IPA.
} 


\section{Revista do SELL \\ v. $4, n^{\circ} .1$ \\ ISSN: $1983-3873$}

Para a análise do pitch, foi marcado o valor da frequência fundamental (F0) para cada sílaba, localizando-a no centro da duração das vogais, isto é, a partir do seu ponto medial. Para a realização dessa etapa, foi preciso trabalhar com dois métodos diferentes: 1) um referente às sílabas vozeadas e 2) outro para as sílabas desvozeadas. Para as sílabas vozeadas, utilizamos a função CTRL + 0 do PRAAT. Com esse comando, foi possível analisar, com pequenas variações, o ponto medial, que, selecionado, vai para o cruzamento de zero mais próximo do ponto médio do segmento. O ponto medial estabelecido depende de como o início e o fim do segmento foi determinado. Essa segmentação é feita por meio de dois procedimentos:

a) uma observação auditiva, levando em consideração as possibilidades articulatórias e as realizações fonéticas da língua;

b) uma análise visual, que interpreta parâmetros acústicos atribuíveis ao segmento, às suas transições e aos vizinhos. (transições).

Para as sílabas desvozeadas, foi feita a seleção da sua parte vozeada e, em seguida, utilizamos a função Picth > get picth do software. Não foi possível utilizar o mesmo método porque, muitas vezes, o ponto médio mais próximo do cruzamento de zero estava na vogal desvozeada ${ }^{7}$.

A análise auditiva seguiu o modelo de Halliday (1970) e Cagliari (2007), sendo feita diretamente pelo pesquisador, sem alteração dos resultados. Os dados não foram julgados por outras pessoas, já que esse tipo de análise requer um treinamento cuidadoso, procedimento que levaria muito tempo e seria inviável para este trabalho.

Tessitura: procedimentos para análise

A tessitura foi analisada a partir da maior e menor frequência nas sílabas, que foram anotadas a partir do recurso do Praat: 1) pitch>get minimum pitch (para a menor frequência) e 2) pitch>get maximum pitch (para a maior frequência). Tanto as sílabas tônicas quanto as sílabas átonas, de cada GT, foram marcadas, mas foram utilizadas somente as de maior e menor frequência. As sílabas desvozeadas não foram consideradas, já que não apresentam variação de $\mathrm{F}^{8}{ }^{8}$. Isso foi feito seguindo a divisão dos enunciados em grupos tonais (GTs), para a análise no modelo de Halliday (1970) /Cagliari (2007).

\footnotetext{
${ }^{7}$ Não utilizamos outro método de análise como, por exemplo, a fronteira do segmento, porque acreditamos que a articulação poderia dificultar e influenciar a segmentação, ou seja, poderia haver interferência das características articulatórias de um som sobre o outro.

${ }^{8}$ As tabelas que apresentam esses valores não serão apresentadas, por uma questão de espaço.
} 


\section{Revista do SELL \\ v. $4, n^{\circ} .1$ \\ ISSN: 1983-3873}

Optamos por utilizar esse recurso do software porque, manualmente, existe uma grande possibilidade de variação, uma vez que os pontos anotados entre uma sílaba e outra, na maioria das vezes, não irão coincidir. Nesse sentido, é mais confiável utilizar a ferramenta fornecida pelo programa, além de ser uma forma de padronização. As opções manuais que podem ser feitas no software não foram completamente descartadas, mas sim, utilizadas como um recurso.

\section{O Padrão entoacional: procedimentos de análise}

Ainda com a intenção de mostrar a correlação entre o modelo acústico e auditivo, foi feita a conversão da forma fonológica dos tons de um modelo para o outro. Para isso, procedemos da seguinte forma: Primeiro, o texto foi segmentado e dividido em 15 frases. Seguido a isso, foi feita a análise auditiva no modelo de Halliday (1970) e Cagliari (1982/2007). Nessa teoria, resumidamente, os enunciados são divididos em GTs. Um GT tem sempre STS que o divide em CPT e CT. O GT inicia-se na STS. Cada componente é dividido em pés, começando na sílaba tônica interna dos componentes. Em relação aos tons primários, Halliday trabalhou com cinco tons primários simples e dois compostos. Cagliari, por sua vez, propôs seis tons primários simples e três tons compostos. Os tons primários são próprios de uma enunciação neutra, diferenciando-se entre si por meio do contorno melódico (CMN) que o GT apresenta no componente tônico. Os tons secundários, em oposição, indicam o uso marcado de um tom, ou seja, trazem consigo uma conotação semântica mais forte do que o tom primário. Os tons secundários são simbolizados pelo número do tom primário correspondente, mais um diacrítico do tipo -, +, entre outros. Em geral, eles acrescentam uma ideia a mais em relação ao significado.

Posteriormente, foi feita a análise acústica a partir do modelo de Pierrehumbert. Para essa descrição são usadas apenas duas unidades tonais $H$ (high/alto) e $L$ (low/baixo), que são anotadas de acordo com a posição de alinhamento com o texto. Ela parte do princípio de que o contorno entoacional é formado por uma sequência de pitch accents e edge tones. Os pitch accents são caracterizados por um tom alto $(\mathrm{H})$ ou por um tom baixo (L), ou pela combinação dos dois tons (chamados de bitonals). $O$ tom principal do pitch accent é simbolizado por um asterisco $\left(^{*}\right)$ - starred tone - e representa a sílaba tônica frasal, o foco entoacional do enunciado como, por exemplo, $H^{*}$ e $L^{*}$. O 


\section{Revista do SELL \\ v. $4, n^{\circ} .1$ \\ ISSN: $1983-3873$}

pitch accent também pode ser formado por um tom secundário. Esse tom é indicado por um hífen sobrescrito, como em: $\mathrm{H}^{-} \mathrm{L}^{-}$.

Os edge tones, por sua vez, estão divididos em acentos frasais e tons de fronteira. Os acentos frasais, como mencionado, são as unidades fonológicas básicas, podendo ser formados por um tom ( $\mathrm{H}$ ou $\mathrm{L})$ ou por um par de tons $(\mathrm{H}+\mathrm{L})$. As sílabas do acento frasal nunca serão marcadas com um asterisco, pois eles são menos salientes que os pitch accents. Esse tom é atribuído entre o último acento frasal e o tom de fronteira, onde ocorre a variação mais notável da F0.

Os tons de fronteira, por sua vez, estão associados ao final da frase entoacional e referem-se ao valor fonológico de um tom. Na notação da autora, eles são indicados por um símbolo de porcentagem (\%) ao lado de cada unidade tonal (H\% ou L\%). Eles serão sempre formados por um único tom. Esses tons estão associados às fronteiras dos domínios prosódicos e não estão relacionados à marcação de proeminência. Esse símbolo também é utilizado para indicar uma marcação de pausa no enunciado.

Por fim, com as análises dos dois modelos teóricos, foi feita a correlação entre eles, para que fosse possível converter a forma fonológica dos tons de um modelo para o outro. Para esse artigo, a conversão feita será apresentada apenas para o tom 1 primário, por uma questão de espaço.

\section{Análise}

\section{Tessitura}

A análise da variação da tessitura foi feita a partir de uma interpretação auditiva. Depois de feita a análise auditiva, os valores acústicos encontrados, tendo em vista a metodologia descrita, foram classificados em: baixo, meio baixo, médio, meio alto e alto. Por meio deles foi possível estabelecer o intervalo de frequência mais baixo e mais alto ( $\mathrm{Hz}$ ou cps), para a definição da tessitura desse informante. Veja na tabela abaixo a distribuição da variação melódica da F0 em função dos cinco tipos de tons da pauta entoacional. 
Tabela 1- Intervalo de frequência que caracteriza os tons, dada a tessitura desse informante e a interpretação auditiva dos tons

\begin{tabular}{|c|c|c|c|c|}
\hline Baixo & Meio baixo & Médio & Meio alto & Alto \\
\hline $\begin{array}{l}\text { entre } 79,9 \quad \mathrm{e} \\
110,0 \mathrm{cps}\end{array}$ & $\begin{array}{l}\text { entre } \quad 110,2 \\
124,3 \mathrm{cps}\end{array}$ & $\begin{array}{l}\text { entre } 124,3 \text { e } \\
141,7\end{array}$ & $\begin{array}{l}\text { entre } 142,7 \text { e } \\
150,0\end{array}$ & $\begin{array}{l}\text { entre } 150,7 \text { e } \\
191,9\end{array}$ \\
\hline
\end{tabular}

Fonte: própria.

Assim, partindo do auditivo, foi possível verificar os valores dos dados acústicos. De acordo com a tabela, vemos que, para esse informante, a tessitura variou de $80 \mathrm{cps}$ a 192cps, aproximadamente. Os valores também mostram que há uma correspondência auditiva bem clara de frequências acústicas para cada faixa de tom. Esse fato confirma a validade das análises auditivas, pois revelou um paralelo entre os níveis de altura melódica e os valores acústicos. Vale salientar que houve uma variação, para mais ou para menos, em alguns níveis melódicos e a faixa de frequência estabelecida. Isso ocorreu para as faixas de frequência dos tons baixo (B), meio baixo (MB), médio (M) e meio alto (MA). No entanto, essas diferenças não foram significativas para inviabilizar a nossa teoria. Pois, para as 23 ocorrências do tom baixo, apenas três tons variaram, para o tom baixo e médio, houve apenas uma variação, em um total de 35 tons para o primeiro e 40 tons para o segundo. Por fim, para o tom meio alto foram encontradas quatro variações em 19 ocorrências desse tom. Assim, para a quantidade total de cada tom, o número de variação das frequências acústicas foi praticamente irrelevante e não descaracterizam a possibilidade de correlacionar dados de uma análise auditiva com dados de uma análise acústica. Para Cagliari (2007, p. 168), essas variações são perfeitamente possíveis, pois "Como trabalhamos com medidas relativas, devemos deixar bem claro que nem sempre os falantes usam medidas rigorosas, por exemplo, em ciclos por segundo, para o que linguisticamente equivale a um mesmo tom". O autor também admite

[...] a possibilidade, não rara, de se ter um tom alto, por exemplo, que, em termos absolutos, tem menos ciclos por segundo do que um tom meio alto, ocorrido pouco antes ou pouco depois, isso porque o falante alterou sua escala entoacional.

(CAGLIARI, 2007, p.168).

Esse fato foi observado em nossos dados com os tons $B, M B, M$ e $M A$, que apresentaram mais ou menos ciclos por segundo, como, por exemplo, um dos casos do tom $B$, com mais ciclos $(127,6)$ por segundo do que a faixa de frequência estabelecida 


\section{Revista do SELL \\ v. $4, n^{\circ} .1$ \\ ISSN: $1983-3873$}

para o tom MB (de 110 a 124,3 cps). Essa diferença de percepção da altura melódica também pode estar relacionada, nesse caso, a uma questão pragmática, ou seja, nesse momento da leitura, o falante pode ter tido a intenção de enfatizar essa passagem do fragmento e, por isso, mudou a tessitura, o que, consequentemente, levou à percepção de um tom mais alto do que o tom anterior.

Outro fato que também pode ser relacionado a essas variações diz respeito à natureza da melodia dos componentes. Sabe-se que cada componente (pretônico e tônico) tem um valor fonológico que é atribuído pelo falante, como uma forma de simplificação dos valores acústicos. No entanto, há variações acústicas que podem interferir de modo mais ou menos significativo na interpretação auditiva dos tons. Quando estamos analisando um componente pelo seu extremo é mais fácil porque as variações não são tão notáveis. Por outro lado, em um padrão em que a característica do CPT é não nivelado, de altura variada, seguindo um padrão que desce/sobe ou, em que o CT apresenta um padrão sobe/desce, por exemplo, as interferências acústicas podem ocorrer mais facilmente.

\section{Os padrões entoacionais - conversão da forma fonológica}

Em relação à análise auditiva foram encontrados 22 grupos tonais, cada um deles identificado com um tipo de tom, sendo 17 tons (12 primários e 10 secundários) de tom 1 e 5 tons (4 primários e 1 secundários) de tipo 3. A maior incidência de tons primários do que secundários mostra que, na maior parte das vezes, o leitor optou por uma leitura menos acalorada, com mais frases afirmativas e declarativas. Ainda assim, os tons secundários foram expressivos durante a leitura, mostrando que o falante também procurou enfatizar, quando necessário, determinadas passagens da história. Para a análise acústica foi preciso, primeiramente, considerar a grade métrica dos enunciados para podermos chegar aos eventos tonais. Pela grade métrica definem-se as sílabas tônicas, descrevendo a relação de força entre elas, e os pés métricos, em um nível superior. Assim, os padrões fonológicos classificados com o GT de tom 1 primário no modelo de Halliday apresentaram a mesma configuração quando transpostos para 0 modelo de Pierrehumbert, ou seja $H+L^{*} L L \%$.

É importante salientar que os padrões fonológicos obtidos para o modelo de Pierrehumbert tiveram como ponto de partida para a sua transcrição o pitch accent ou STS. Isso porque, para a autora, o que vem antes do acento nuclear não é relevante para a análise; o que interessa é o alvo, isto é, o final do movimento a partir da sílaba mais 


\section{Revista do SELL}

v. $4, n^{\circ} .1$

ISSN: $1983-3873$

proeminente, servindo como ponto de ancoragem. Para esse modelo, é o fato fonético e não o fonológico que está em discussão.

$\mathrm{Na}$ análise feita por Halliday (1970), o tom 1 caracteriza-se por ter um movimento tônico descendente com tendência terminal baixa ou média baixa. No modelo de Cagliari (2007), para o PB, esse mesmo tom é descrito por ter um componente tônico com um padrão descendente médio-baixo. Em nossos dados, o tom 1 primário também apresentou esse mesmo padrão entoacional descendente, tanto em comparação com o modelo de Halliday quanto com o de Pierrehumbert. Portanto, segundo a nossa análise, o tom representativo das declarativas neutras finais para o PB, segundo o modelo de Pierrehumbert é $H+L^{*} L L \%$, iniciando-se com uma F0 mais alta e, em seguida, mantendo-se em queda na posição final do enunciado. Em todas as frases analisadas, esse padrão ocorreu nas palavras focais em final de enunciado, mais especificamente com tom L alinhado à penúltima (E1 - GT3/ E2 - GT2/ E6/ E9/ E15 - GT2) e última (E1 - GT2/ E8/E13 - GT2) ${ }^{9}$ sílabas.

Veja um exemplo da configuração da curva melódica no sentido da queda da $\mathrm{Hz}$, para o modelo de Pierrehumbert (figura $2 b$ ) e de acordo com os pontos auditivos propostos para a anotação de Halliday em nossos dados (figura 2a). E, ao lado, uma análise proposta pela autora, apresentada no apêndice da sua tese de doutorado, que segue o mesmo padrão da nossa análise:

Figura 2a - Exemplo de configuração da curva melódica de acordo com o modelo auditivo.
Figura 2b - Exemplo de configuração da curva melódica de acordo com o modelo acústico
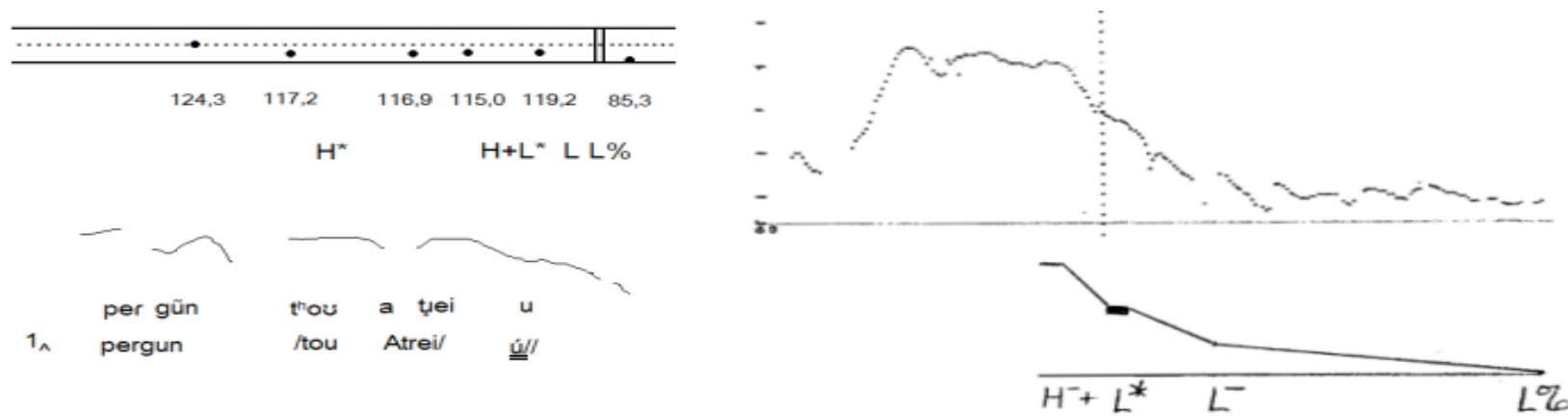

Nas figuras (2a) e (2b) vemos a tendência à declinação da curva melódica. $\mathrm{Na}$ figura (2a), as bolinhas cheias marcam o valor auditivo relativo da variação melódica que foi atribuído a cada sílaba. Abaixo dessas três linhas, mostra-se o valor obtido para a F0 em números. Posteriormente, segue a análise acústica a partir do modelo autossegmental de Pierrehumbert (1980), em seguida, vem representado o contorno da

\footnotetext{
${ }^{9}$ Esses exemplos estão especificados no fragmento do texto em anexo.
} 


\section{Revista do SELL}

v. $4, n^{\circ} .1$

ISSN: $1983-3873$

curva melódica de F0. E, por fim, aparece a transcrição fonética acompanhada da transcrição ortográfica, juntamente com a atribuição do tom característico, juntamente com a informação dos GTs (//) e da STS, que está destacada por dois traços que a sublinha e ocorre imediatamente após as barras verticais duplas (II). O diacrítico $(\wedge)$ representa a sílaba tônica silenciosa, que ocorre imediatamente após os números que indicam o tom do enunciado.

No exemplo (2b), de Pierrehumbert, a linha vertical mostra o início da sílaba sobre a qual o foco recai, ou seja, a sílaba bult da palavra bulldozer (de acordo com o exemplo da autora) Ao compararmos essa curva melódica com a mostrada na figura (2a), observaremos um padrão entoacional descendente, que começa alto na sílaba átona e, em seguida, sofre uma queda em direção à sílaba tônica. Esse fato foi recorrente em todos os outros enunciados que apresentaram esse padrão. Sendo assim, o padrão proposto para as declarativas neutras em nossos dados é, acusticamente, $\mathrm{H}+\mathrm{L}^{*} \mathrm{~L} \mathrm{~L} \%$ e, auditivamente,

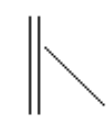

Vale salientar que os CPTs variaram entre uma pretônica média nivelada e baixa nivelada. No entanto, sua configuração não é essencial para a definição do padrão entoacional em um enunciado, por isso, não vem representado no modelo acima.

Quanto aos tons secundários e primários (de tipo 3) não apresentados neste artigo, também foi possível chegar a uma correspondência entre as abordagens. Vale salientar que os tons de tipo 3 (primário e secundário) apresentaram uma curva melódica ascendente. Assim sendo, para o tom 1 e suas variações, a tendência da curva melódica foi caracterizada no sentido da queda da $\mathrm{Hz}$, podendo vir de $\mathrm{H}>\mathrm{L}$ ou de $\mathrm{L}>\mathrm{L}$. Já para o tom 3 e suas variações, a tendência da $\mathrm{Hz}$ foi no sentido da elevação da $\mathrm{Hz}$ vindo sempre de $u m \mathrm{H}>\mathrm{H}$.

\section{Conclusão}

Este artigo tinha como objetivo fazer uma análise comparativa entre os dados acústicos e auditivos a partir de alguns dados do Português do Brasil. Nossa hipótese era a de que, quando correlacionadas, as análises acústicas e auditivas (e vice-versa) complementavam-se. Para isso, este estudo tomou como base dois modelos teóricos, 


\section{Revista do SELL}

v. $4, n^{\circ} .1$

ISSN: $1983-3873$

um de base acústica (modelo Autossegmental) e outro de base auditiva (modelo Funcional).

No desenvolvimento deste artigo, a suposição foi confirmada, mostrando que não só é possível como também viável estabelecer um paralelo entre as duas metodologias (acústica e auditiva), já que a análise acústica acoplada à análise auditiva ajuda a conciliar os detalhes da fala com as unidades fonológicas do sistema da língua.

A comparação entre as duas abordagens metodológicas mostrou que mesmo sendo distantes teoricamente um do outro, apresentam aspectos formais que permitem estabelecer uma relação entre eles. Em outras palavras, a análise proposta por Halliday revelou-se um bom modelo para ser comparado com análises acústicas, enquanto a abordagem de Pierrehumbert mostrou que a interpretação dos tons, que vem de análises acústicas, também pode ter uma avaliação auditiva. Dessa maneira, os dois modelos teóricos ajudam a esclarecer os fatos que a outra abordagem não consegue tratar adequadamente. A conversão da forma fonológica dos dois modelos descritivos também ajudou na comparação entre eles e justificou, mais uma vez, a sua semelhança e proximidade.

A análise da tessitura também revelou a possibilidade dessa correlação, pois estabelecidas as faixas de frequência, auditiva (alturas melódicas) e acústica (análise da F0), observamos a equivalência entre os dois modelos. As variações foram pouco expressivas e não foram suficientes para inviabilizar os resultados. Elas apenas mostraram os ajustes que o ouvido faz durante a percepção da curva entoacional.

Nesse sentido, chegamos à conclusão de que o mais viável é realizar trabalhos que façam uma interpretação da entoação levando em consideração o ponto de vista perceptivo (fonologia funcional) e o ponto de vista acústico (fonologia autossegmental). Atualmente, os trabalhos referentes aos estudos entoacionais estão mais voltados para a questão estatística. Não há uma preocupação com a natureza auditiva, já que há uma dúvida quanto à sua confiabilidade. No entanto, este artigo mostrou que isso é possível, uma vez que em 135 tons, apenas em 6,66\% dos casos houve uma variação entre o auditivo e o acústico. Fato que pode ocorrer, já que para o ouvido esses resultados são irrelevantes no conjunto da frequência, pois eles ocorrem como variação da curva melódica que não é stead state, ou seja, não tem valores fixos, mas pequenos altos e baixos, que são homogeneizados pelo ouvido. Esses resultados são interpretados em função do contexto em que ocorrem, considerando a tendência da curva melódica. 


\section{Revista do SELL}

v. $4, n^{\circ} .1$

ISSN: $1983-3873$

$\mathrm{Na}$ realidade, é necessário saber lidar com realidades diferentes, como, por exemplo, reconhecer a importância da colaboração entre as análises acústicas e auditivas, mesmo que elas não apresentem uma relação amigável entre si. O cérebro humano não é capaz de distinguir certas variações físicas da frequência fundamental e os dados acústicos vêm apoiar o que o ouvido processou, mostrando detalhes que ajudam o linguista a correlacionar fatos da fala com fatos do sistema da língua, pois

Os olhos que veem os espectrogramas são ajudados pelos ouvidos que interpretam os sons como unidades psicoacústicas, interiorizadas na mente dos falantes, como resultado de um processo de aquisição da linguagem.

(CAGLIARI et alli, 2012, p. 11).

\section{Referências}

ABERCROMBIE, D. Elements of general phonetics. Edinburgh: Edinburgh University Press, 1967.

BALL, M. J.; RAHILLY, J. Phonetics: the science of speech. London: Arnold. 1999. BOIX, J. L. Introducción a la fonética: el método experimental. Barcelona: Anthropos, 1991.

CAGLIARI, L. C. Elementos de fonética do Português Brasileiro. 1982. 192f Tese (Livre docência em Linguística) - Universidade Estadual de Campinas, Campinas, 1982. . Elementos de fonética do Português Brasileiro. São Paulo: Paulistana,

2007.

Prosódia: ontem e hoje. In: FONSECA-SILVA, M. C.; PACHECO, V.; LESSA-DE-OLIVEIRA, A. S. C. (Org.). Em torno da lingua(gem): questões e análises. 1 ed. Vitória da Conquista: Edições UESB, 2007b, v. 1, p. 15-40.

A entoação no componente fonológico da gramática. 2011, p.1-3 (ms). CAGLIARI, L. C.; CARVALHO, M.; GEMENTI, M. M. A questão da fonética acústica e auditiva dentro e fora dos laboratórios. GSCP, Belo Horizonte, 2012, p. 1-24 (ms). CAGLIARI, L. C; MASSINI-CAGLIARI, G. O papel da tessitura dentro da prosódia portuguesa. In: CASTRO, I.; DUARTE, I. Razões e emoção: miscelânea de estudos em homenagem a Maria Helena Mateus, 2003, v.1, p. 67-85. Disponível em:

<http://www.fl.ul.pt/dlgr/mateus/mateus.htm>: Acesso em 18 jun. 2010.

CRYSTAL, D. Prosodic systems and intonation in English. Cambridge: Cambridge University Press. 1969.

CATFORD, J. C. A practical introduction to phonetics. Oxford: Clarendon Press. 1988. CRUZ-FERREIRA, M. M. F. Non-Native comprehension of intonation patterns in Portuguese and in English.1983. 421f. Tese (Doutorado em Filosofia) - Faculdade de Artes, Universidade de Manchester, Manchester, 1983.

CURRIE, K. L. Intonation systems in Scottish English. Tese (PhD thesis), University of Edinburgh, 1979.

ENDE, M. História sem fim. São Paulo: Martins Fontes, [19--].

FANT, G. Descriptive analysis of the acoustic aspects of speech. In: LEHISTE, I. (Ed.). Reading in acoustic phonetics. Cambridge: The M.I.T. Press. 1967. p. 93-107. 


\section{Revista do SELL \\ v. $4, n^{\circ} .1$ \\ ISSN: $1983-3873$}

FRY, D. B. Linguistic theory and experimental research. In: JONES, W. E.; LAVER, J. (Ed.). Phonetics in linguistics: a book of readings. London: Longman. 1973. p.66-86. HALLIDAY, M.A.K. A course in spoken english: Intonation. London: Oxoford University Press, 1970.

Units in the perception and production of speech. Three areas of

experimental phonetics. London: Oxford University Press.1967, p. 143-172.

JOHNSON, K. Acoustic and auditory phonetics. 6. ed. Oxford: Blackwell, 2003.

JONES, D. An Outline of English Phonetics. 9. ed. Cambridge: Cambridge University

Press, 1960. (1st ed. 1917).

LIBERMAN, A. M. The intonation system of English. PhD thesis, MIT, 1975.

LIBERMAN, M.; PRINCE, A. On stress and linguistic rhythm. Linguistic Inquiry, n. 8, p. 249-336, 1977.

LYONS, J. Lingua(gem) e linguística: uma introdução. Rio de Janeiro: LTC, 1897, p. 161175.

MALMBERG, B. The linguistic basis of phonetics. In: Manual of Phonetics.

Amsterdam: North-Holland Publishing Company, 1968, p.1-16.

MARTIN, J. G. Rhythmic expectancy in continuous speech perception. In: COHEN, A.; NOOTEBOOM, S. C. (Ed.). Structure and process in speech perception. New York: Springer-Verlag, 1975.

NEVES, M. H. M. A gramática funcional. São Paulo: Martins Fontes, 1997.

PIERREHUMBERT, J. The Phonology and phonetics of english intonation. 1980. $402 \mathrm{f}$.

Tese (Doutorado em Linguística) - Department of linguistics and philosophy,

Massachusetts Institute of technology, Indiana University Linguistics Club, 1980.

PIKE, K. L. The intonation of American English. Ann Arbor: The University of Michigan

Press. 1945.

WINCKEL, F. Acoustical foundations of phonetics. In: MALMBERG, B. (Ed.). Amsterdam:

North-Holland Publishing Company, 1968, p. 17-44.

YI, XU. In defense of lab speech. Journal of phonetics, London, v. 38, p.329-336, Apr. 2010.

ANEXO A - Transcrição ortográfica e fonética do texto analisado, com anotação dos respectivos GTs e tons.

(E1) Quem é você?, perguntou Atreiú, e aproximou-se mais um passo

$/ / 1+$ Khẽ̃̃n $\varepsilon$ vose pergũnthov atıeiu,// //1e aprosimousi mais ũm pasv//

(E2) Sou Gmork, o lobisomem

//+1sou gimosgi// //1v lobizomẽ̃̃//

(E3) Por que está preso aqui?

//1-pur ke ista prezu akhi//

(E4) Esqueceram-se de mim quando se foram embora

//3 Iskeserẽ̃̃ si di mĩn // //1-kẽundu si for̃im bora//

(E5) Quem?

//1+khẽ̃̃n//

(E6) Aqueles que me prenderam com esta corrente

//1 akhelis kI mi prenderẽ̃̃n kũ \&sta koxeintr//

(E7) E para onde foram?

//:1 i para õndi forũ//

(E8) Gmork não respondeu 


\section{Revista do SELL}

v. $4, n^{\circ} .1$

ISSN: $1983-3873$

//1 gimsıge nẽ xespõndeひ//

(E9) Olhou Atreiú com os olhos meio fechados

//1 oরou atereiu kõ us oরus meiu fejadus//

(E10) Depois de um longo silêncio, disse:

//3 depoiz di ũ lõũgu silễ̃̃sı //1- distol/

(E11) Você não é daqui,

//3+vose nũ $\varepsilon$ dakhi//

(E12) pequeno estrangeiro,

//-1 pekhenu esterẽzeiru//

(E13) não é desta cidade nem deste país

//3 nẽ $\varepsilon$ desta sidadI// //1 nẽ̃̃n destı pais//

(E14) $O$ que procura?

//+1 $v$ khI perokhura//

(E15) Atreiú baixou a cabeça.

//3 atereiu// //1 barjou a kabesa.// 